\title{
Money Stock Control Under Alternative Definitions of Money
}

\author{
JOHN A. TATOM
}

\begin{abstract}
I $\mathrm{N}$ recent years, existing definitions of the monetary aggregates have come under increasing attack. Initially, this assault stemmed from allegations that money demand had shifted in 1974 and that the conduct of monetary policy required new measures which were more closely related to the concerns of policy, such as total spending and prices. ${ }^{1}$ It has also become apparent that changes in technology, regulations, and financial market institutions have had a significant effect on the payments process and, perhaps, the link between existing aggregate measures and economic activity. An important example of such a change was the introduction of automatic transfer services (ATS) and the extension of NOW accounts to the state of New York on November $1,1978,{ }^{2}$ Other innovations include the increasing volume of repurchase agreements, money market mutual funds, and regulatory changes that now allow corporations and state and local governments to hold savings accounts.
\end{abstract}

In response to these concerns, the staff of the Board of Governors of the Federal Reserve System proposed new definitions for $\mathrm{M} 1, \mathrm{M} 1+, \mathrm{M} 2$, and $\mathrm{M} 3$ monetary aggregates in the January 1979 Federal Reserve Bulletin..$^{3}$ The principal criteria underlying the redefinitions were to improve the ability of the Fed to control output and inflation and to combine deposits that are close substitutes for each other.

The staff's proposal has generated considerable comment both within and outside the Federal Reserve

\footnotetext{
1See S. M. Goldfield, "The Case of the Missing Money,"Brookings Papers on Economic Activity (3/1976), pp. 683-789, and Jared Engler, Lewis Johnson, and John Paulus, "Some Problems of Money Demand," Brookings Papers on Economic Activity (1/1976), pp. 261-280.

The problems of controlling a broader measure of $\mathrm{M} 1$, inclucting new ATS and NOW account balances, with existing meastres and policy procedures are discussed in John A. Tatom and Richard W. Lang "Automatic Transfers and the Money Supply Process," this Review (February 1979), pp. 2-10.

"See "A Proposal for Redefining the Monetary Aggregates," Federal Reserve Bulletin (Jamuary 1979), pp. 13-42.
}

System. Most critics are in favor of the effort to redefine the aggregates but find fault with the specific measures proposed. The criticisms center on (1) the exclusion of certain means of payment from the proposed M1 measure, (2) the questionable improvement of the relationship of the proposed measures to spending, or of the stability of the demand for money, and (3) disagreements over whether the proposed measures adequately meet the staff's criterion of combining deposits that are close substitutes.

The actual redefinitions that will be forthcoming, if any, are still unknown. Nonetheless, it is useful to examine the issue of money stock control with the measures initially proposed in January 1979. The primary criticism of these measures, from the viewpoint of control, is that timely data from thrifts and other financial institutions have been unavailable. To the extent that the Federal Open Market Committee uses the proposed measures instead of existing measures for targeting aggregate growth, the relationship between the instruments of monetary policy and the different aggregate measures is of considerable importance, regardless of timely data availability. Moreover, any definitions of monetary aggregates that ultimately will be chosen are unlikely to deviate significantly from those examined here.

The issue of controllability is especially important in view of the October 6, 1979, announcement of a Federal Reserve System policy change to improve control over the growth of monetary aggregates by placing greater emphasis on the supply of bank reserves in day-to-day operations. This action represents both a fundamental change in the focus of monetary policy and a clearer recognition of the link between Federal Reserve actions that affect bank reserves and the monetary aggregates which it seeks to control. This article examines the proposed definitions of mone tary aggregates as an example of the type of control consideration required by this shift in policy. The re- 
sults indicate that the proposed aggregate measures are less controllable than existing aggregates, although only slightly less so for proposed M1.4

\section{EKSTRN AND RPOPOSED MONETARY AGGREGATES}

The major changes in the proposed redefinitions of monetary aggregates are designed to account for demand-deposit type accounts that are not classified as demand deposits, and to aggregate assets by type, irrespective of the institution involved in the creation of such assets. With regard to the first change, proposed Ml would include NOW accounts, demand deposits at thrift institutions, credit union share drafts, and savings accounts at commercial banks that are subject to automatic transfers to demand accounts. This change is especially important after November 1978, when NOW accounts were extended to New York State and ATS was introduced nationwide. Before then, NOW accounts at commercial banks and thrifts, as well as credit union share draft balances, were relatively small. Also, as recommended by the Bach Committee, deposits held by foreign institutions at domestic banks are excluded from the proposed M1 measure.

The attempt to aggregate similar monetary assets regardless of issung institution is especially important in the proposed measures of M2 and M3. Currently, M2 is equal to M1 plus other deposits at commercial banks - including NOW accounts, ATS savings accounts, other savings accounts, time deposits, and CDs

4Other studies have shown that money demand estimates and the link between intermediate monetary aggregate measures (M1, M2, M3) and GNP are not improved by the proposed measures. See, for example, the staft study, "A Proposal for Redefining the Monetary Aggregates," and Laxience H. Meyer and Murray L. Weidenbam "Fed's Proposed Redefinition of Monetary Aggregates Seen Falling Short of Goal," The Money Manager (May 7, 1979), Together with the results here, it can be concluded that the link between the monetary base and GNP will be worse under the proposal, as long as intermediate targeting is used. This is significant for the conduct of monetary policy. Andersen and Kamosky have shown that the mean and variance of torecast errors of GNP using the monetary base are not significantly worse than occtirs using existing M1 or M2 measures. Adoption of the proposed measures would therefore increase the desirability of targeting on the monetary base instead of intermediate monetary aggregates. See Leonall $\mathrm{C}$. Andersen and Denis $\mathrm{S}$. Karnosky, "Some Considerations in the Use of Monetary Aggregates for the Implementation of Monetary Policy," this Review (September 1977), pp. 2-7.

"See Advisory Committee on Monetary Statistics, "Improving the Monetary Aggregates," Federal Reserve Board of Governors, June 1976. Mlt is not revised in the proposal except for the exclusion of foreign balances. Currently, $\mathrm{MI}+$ is the same as proposed M1 plus other savings accounts at commercial banks. This measure is not discussed here. (except large CDs at weekly reporting banks). The proposed M2 (PM2) would add to proposed M1 (PMI) savings accounts at both commercial banks and thrifts. Consequently, it would differ from the current measure of $\mathrm{M} 2$ primarily in its exclusion of time deposits at commercial banks and its inclusion of demand, NOW, and other savings balances at thrifts, and credit union share drafts.

M3, by existing definitions, differs from $M 2$ in its inclusion of time and savings deposits at thrifts and credit unions. Since all but time deposits at these institutions are in PM2, proposed M3 (PM3) is intended to reflect the distinction between savings and time accounts. Thus, PM3 is PM2 plus all time deposits and CDs at commercial banks and thrifts. PM3 differs from $\mathrm{M} 3$ in its inclusion of large $\mathrm{CDs}$ at weekly reporting banks and demand deposits at thrifts ( $\$ 864$ million in June 1978). Except for the latter difference, PM3 is essentially the same as the existing aggregate M5. Existing measures M4 and M5 will be dropped according to the proposal. Table 1 summarizes these differences. ${ }^{6}$

The proposal for aggregating over similar types of deposits rather than similar institutions is not without shortcomings. The rationale for the change is based upon an increase in substitutability of deposits among institutions. ${ }^{7}$ It is unclear, however, whether the substitutability of these deposits has increased. Barnett has shown, for example, that there is no significant substitutability between small time deposits at commercial banks and savings and loans, before or after 1974. Also, his evidence shows increases in substitutability between deposits within institutions, making the M2 aggregate a more justifiable measure than before on this criterion. ${ }^{8}$

The proposed redefinitions also ignore the question of whether other assets should be included in the monetary aggregates, or where they might be likely candidates for inclusion. For example, Wenninger and Sive-

This table is adapted from one oniginally used by John Wenninger and Charles M. Sivesind, "Defining Money for a Changing Financial System," Federal Reserve Bank of New York Quarferly Review (Spring 1979), pp. 1-8.

TSee Williarn A. Bamett, "Substitutability, Aggregation and Superlative Quantity Indices," Mernorandum, Federal Reserve Board of Governors, April 17, 1979, processed, and "A Fully Nested System of Monetary Quantity and Dual User Cost Price Aggregates," (Board of Governors of the Federal Reserve System, Division of Research and Statistics, Econometric and Computer Applications Section, November 1978; processed).

8These points have been made by Kenneth $C$. Froewiss, John P. Judd, Michael W. Keran and John L. Scadding, "Comments on Redefining the Monetary Aggregates," (Federal Reserve Bank of San Francisco, July 5, 1979 , processed). 
Toble 1

\section{Comparison of Current and Proposed Definitions of the Nonetary Aggregates}

\begin{tabular}{|c|c|c|c|c|c|c|}
\hline \multirow[b]{2}{*}{ Conponents } & \multicolumn{2}{|c|}{ MI } & \multicolumn{2}{|c|}{$n 2$} & \multicolumn{2}{|c|}{ M3 } \\
\hline & Cunrent & Poposed & Current & Proposed & Curren: & 8 roposed \\
\hline cunency h olsuloten & $\chi$ & $x$ & 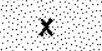 & $x$ & $x$ & $x$ \\
\hline A Conmercial Banks & & & & & & \\
\hline Demand deposits & $x$ & $x$ & $x$ & $x$ & $x$ & $x$ \\
\hline Now accounts & & $x$ & $x$ & $\mathbf{x}$ & $x$ & $x$ \\
\hline Savings subject to outonnatic tronsfer & & $x$ & $x$ & $x$ & $x$ & $x$ \\
\hline Ohhe sovengs occouns? & & & $x$ & $x$ & $x$ & $x$ \\
\hline Snoll time deposifs & & & $x$ & & $x$ & $x$ \\
\hline lorge tine deposits? & & & $x$ & & $x$ & $x$ \\
\hline cost & & & & & & $x$ \\
\hline At thin lnstinutionss & & & & & & \\
\hline Denand deposils & & $x$ & & $x$ & & $x$ \\
\hline Now accounts & & $x$ & & $x$ & $x$ & $x$ \\
\hline onher sovings occounts & & & & $x$ & $x$ & $\mathrm{x}$ \\
\hline other line deponts & & & & & $x$ & $x$ \\
\hline Credil union thore drafts & & $x$ & & $x$ & $x$ & $x$ \\
\hline
\end{tabular}

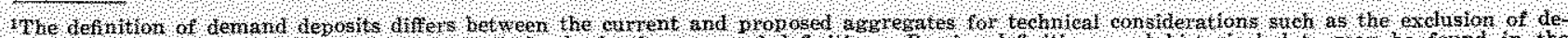

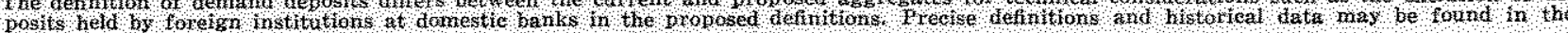
Tederal Rererot Bulleth.

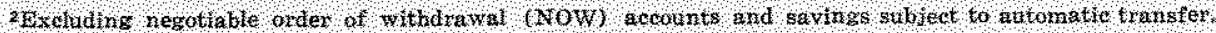

$\$ 106000$ mono

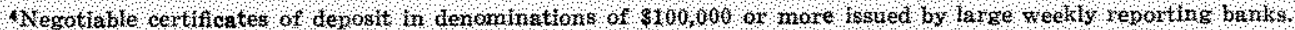

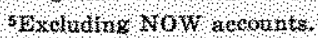

sind question the omission of repurchase agreements, (RPs), money market mutual funds (MMMFs), and new savings balances of state and local governments and corporations, and suggest a broader definition of the money stock, M1." Meyer and Weidenbaum also argue that RPs and MMMFs should probably be included in a new measure of M1 and/or M2.10

The major tests of the usefulness of the proposed aggregates have consisted of studies of the comparative predictive performance of the proposed vs. existing aggregates in money demand equations and in the estimation of GNP in reduced form equations (both within sample and out-of-sample). Generally, the evidence does not indicate that the proposed measures are an improvement over existing measures. ${ }^{11}$

\section{CONTPOLNADERV}

Andersen and Karnosky have provided a useful analytical framework for the choice of a monetary aggregate target. ${ }^{12}$ They argue that Federal Reserve actions

9See Wenninger and Sivesind, "Defining Money."

IOSee Meyer and Weidenbaum, "Fed's Proposed Redefinition,"

11See, for example, Meyer and Weidenbaum, "Fed's Proposed

Redefinition" or the staff study, "A Proposal for Redefning the Monetary Aggregates."

1"See Andersen and Kamosky, "Some Considerations in the Use of Monetary Aggregates." determine the adjusted monetary base which, in turn, affects monetary aggregates. Intermediate monetary aggregates influence spending decisions and, consequently, are an indicator of nominal GNP. In order to determine the selection of an intermediate aggregate, the forecasting accuracy of reduced-form equations for GNP can be compared. However, to determine the Fed's ability to influence GNP, they argue, analysts must consider not only the variance of GNP estimates, given an intermediate money aggregate target, but also the relative size of errors in achieving the intermediate monetary aggregate target. ${ }^{13}$

This framework is useful in considering the desirability of conducting policy by controlling the proposed measures. There is no evidence that the proposed measures represent an improvement over

13They conclude that, even if there is zero control error in the achievement of intermediate monetary aggregate targets, control of the base itself resalts in no worse an ability to influence nominal GNP. This conclusion is reinforced by the results below, if the proposed measues are adopted. It is conceivable that the relitionship between total spending and existing aggregate measures could have worsened in recent years because of the introduction of new means of payments or other financial assets. In this case, the proposed measures might represent an inprovement for policy purposes, despite the lack of evidence using past data. Andersen and Karnosky performed tests for structural change in the relationship between spending and $M 1, M 2$, and the monetary base for the period after II/1971 in their equations which are estimated over the period I/1952-IV/1975. The tests rejected such a change in the relationships. 
existing measures as intermediate targets in controlling spending. Thus, the question arises whether the proposed measures might improve policymaking by reducing the control errors linking Federal Reserve actions and intermediate aggregate measures. If the proposed measures are controllable with less error, they would represent an improvement over existing measures for policy purposes, and the evidence would strengthen the case for intermediate targeting. On the other hand, if the proposed aggregates do not exhibit more precise control, the case for using the proposed measures as intermediate targets is serioksly weakened. ${ }^{14}$ The evidence below shows that the proposed measures are less controllable.

A simple model linking equilibrium money stocks to the adjusted monetary base can be used to assess the controllability of monetary aggregates. In equilibrium, a monetary aggregate $\mathrm{M}_{t}^{*}$ may be thought of as the product of the adjusted monetary base (MB) and a money multiplier $(k)$. Converting this relationship to logarithms (In) results in the expression: $\ln \mathrm{M}^{*}=$ $\ln \mathrm{k}+\mathrm{ln} \mathrm{MB}$. Thus, changes in a monetary aggregate are related to changes in the adjusted monetary base and/or the money multiplier for this aggregate measure. Federal Reserve actions determine the adjusted monetary base, but the money multiplier is influenced by the decisions of households, businesses, and financial institutions. Consequently, the ability to control a monetary aggregate requires that the money multiplier be predictable. Variations in the money multiplier cause control errors in achieving a given amount in a monetary aggregate through actions affecting the adjusted monetary base.

A model to assess the variance of monetary aggrem gates (or the money multiplier), given the monetary base, may be written as

$$
\ln M_{t}^{*}=\beta_{0}^{*}+\beta_{1}^{*} \ln M_{t}+\beta_{2}^{*}
$$

where $t$ is included to allow for a time trend in the money multiplier. Since changes in the adjusted monetary base may not result in instantaneous adjustment of the equilibrium money stock, an adjustment process can be specified as

$$
\ln \mathrm{M}_{\mathrm{t}}-\ln \mathrm{M}_{\mathrm{t}-1}=\lambda\left(\ln \mathrm{M}_{\mathrm{t}}^{*}-\ln \mathrm{M}_{\mathrm{t}-\mathrm{t}}\right)
$$

which states that actual changes in the monetary aggregate are some proportion $\lambda$ of the discrepancy between equilibrium and past levels of the monetary

\footnotetext{
14This also implies that the adoption of the proposed measures would reinforce the case for targeting on the monetary base instead of $\mathrm{Ml}$ or a higher order $\mathrm{M}$.
}

aggregate. Combining equations 1 and 2 , the model may be estimated in the form ${ }^{15}$

$$
\text { (3) } \Delta \ln M_{t}=\beta_{v}+\beta_{\mathrm{E}} \Delta \ln \mathrm{MB}_{\mathrm{t}}+\beta_{2} \Delta \ln \mathrm{M}_{\mathrm{t}-\mathrm{x}}
$$

where the parameters of the model, excluding $\beta_{0}$, may be obtained from

(4)

$$
\begin{aligned}
& \lambda=1-\beta_{2} \\
& \beta_{1}^{*}=\frac{\beta_{2}}{1-\beta_{2}} \\
& \beta_{2}^{*}=\frac{\beta_{0}}{1-\beta_{2}}
\end{aligned}
$$

This model is estimated for the period $1 / 1960$. II/1978 for existing aggregates M1, M2, and M3 and the proposed aggregates PM1, PM2, and PM3. ${ }^{16}$ Differences in the logarithms of monetary aggregates and the adjusted monetary base are multiplied by 400 in order to express annual growth rates. A summary of the estimated equations is given in table 2 , where $\beta_{0}$ is omitted when it is insignificant. The equations for the growth rates of $\mathrm{M} 1$ and $\mathrm{PMI}$ do not exhibit significant autocorrelation (at the 1 percent level). The equations for the higher aggregates, both existing and proposed, are estimated using the Hildreth-Liu technique to control for the significant first-order autocorrelation of growth rates. The Durbin-Watson $\mathbf{h}$-statistic indicates the absence of remaining autocorrelation. The significant autocorrelation coefficient for higher

\footnotetext{
15. Estimating the model using equation 3 instead of its coumterpart in level-form is motivated primarily by policy makers interest in controlling aggregate growth. In addition, significant antocorrelation exhibited in the level equations cannot be removed for the aggregates M2, PM2, M3, and PM3 using a first-order antocorrelation adjustment. Thus, in the level-form, the results and experiments below wonld be biased. Whether the money multiplier for each aggregate is better explained by a model other than that inplicit in equations $1-3$ is beyond the scope of this paper. The model is not intended to represent the best means for fore. casting money. For a recent work on modeling the money maliplier which is more useful for operational purposes, see James M. Johannes and Robert H. Rasche, "Predicting the Money Muttiplier," Journal of Monefary Economics (suly 1979), pp. 301-325.

lisince some analysts expect the federal funds rate to be important in money stock control, the logarithm of this variable was added to equation 1, resulting in the addition of the first-difterences of the logarithrn of the rate to the estiinated equation 3 . The resuting estimates for the six equations failed to reveal a significant impact of the federal funds rate on the equiltbrium stock of each aggregate. Since sone of the newer deposits such as NOW accounts did not begin until later in the sample period, a check of the relationship of the series was conducted by compuning cor relation coefficients over the first and last half of the sample. Lxisting and proposed meastres have correlation coefficients of $.99+$ in both subperiods. Comparing correlations of $\Delta$ lns fais to reveal any substantial detejioration in the relations, as welt. For the period $1 / 1960-1 \mathrm{~V} / 1968$, and $1 / 1969-I E / 1978$, the correlation coeflcients of $\Delta$ ln $M 1$ and $\triangle 1+\mathrm{PM}$ are 0.98 and 0.97 , respectively. For $\mathrm{M} 2$ and PM2, comparable coeffeients are 0.38 and 0.79 ; for $M 3$ and PM3, the correlation coefficients are 0.96 and 0.89 , respectively.
} 


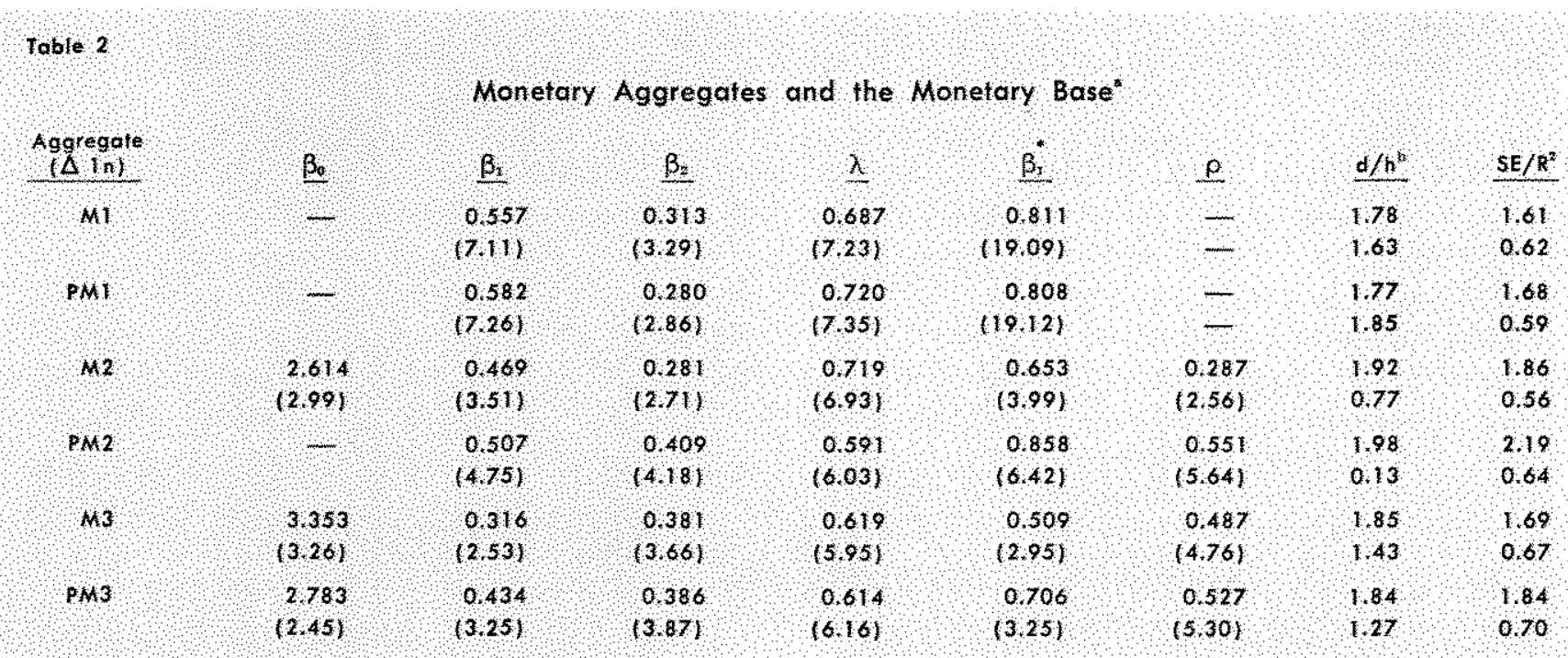

The undoers n parentheses ane $1 \mathrm{stat}$ isties

The Dubn Watson a and h stathto, resped wely.

order M's may be due to omitted variables or simply the structure of the error process. In either case, control of these aggregates via adjusted monetary base targeting is more difficult because it requires finding and forecasting the omitted variables or accounting for the autocorrelated errors. In all six equations, the model fits the data quite well judging by the $R^{2}$ and the significance of $\beta_{1}$ and $\beta_{2} .{ }^{17}$

The growth rate of the existing aggregate measure is more controllable - as shown by its smaller standard error - than the proposed measure for each of the three M's. Both MI and PM1 are more controllable than the higher order M's. For M1, PM1, and $\mathrm{M} 2$, the equilibrium adjustment process for a change in $\mathrm{MB}$ is 90 percent complete within two quarters. While the M3 equations have smaller standard errors than those for $\mathrm{M} 2$, the lagged adjustment process is longer ( $\operatorname{smaller} \lambda$ ) for M3 than for M2, but slightly shorter for PM3 than for PM2. ${ }^{18}$

Of course, the more important test of controllability is whether the equations in table 2 forecast well in dynamic simulations. Table 3 presents the results for within-sample dynamic simulations of the six equa-

\footnotetext{
17 Formulas for computing the variance of the restricted parameters $\left(\beta^{*}\right)$ may be found in Jan Kementa, Elements of Econometrics, (New York: The Macmillan Company, 1971), p. 444

18 Similar equations were estimated nsing the net source base instead of the monetary base as the control variable. The results from the comparisons above were the same, but the standard error of the equations was higher in each case. The most striking result of those estimates is that $\beta_{1}$ and $\beta_{3}^{a}$ are not significantly different from zero for M2, PM2, M3, or PM3. Thus, control of the source base alone has no impact on aggregates other than MI or PMI.
}

tions reported in table 2 . The simulations of the quarterly growth rates (annualized percentage-point differences in logarithms) perform remarkably well for all of the measures except PM2, according to the mean errof over the whole sample period. PM2 growth is apparently underestimated on average. The root-meansquared error (RMSE) compares favorably to the standard errors reported in table 2 for $\mathrm{Ml}, \mathrm{PMl}$, and M2. The RMSE is substantially higher than the standard error for PM2 and PM3, as well as for the existing M3 measure. Control of these aggregates via the monetary base is poor according to the dynamic simulations.

The controllability of the growth rate of the existing measures is greater than that of the proposed measures, as judged by the error statistics reported in table 3. According to the RMSE and mean absolute errors, the controllability of existing aggregates de-

Table 3

Dynamic Smulations of Aggregate Growth Rates $1 / 1960-11 / 1978$

\begin{tabular}{|c|c|c|c|}
\hline Aggregate & $\begin{array}{l}\text { Rool-Aedrat } \\
\text { Squared Error }\end{array}$ & Mear Absolute & $\begin{array}{l}\text { Mean } \\
\text { Errot }\end{array}$ \\
\hline$M 1$ & $170 \%$ & $13 \%$ & $0.03 \%$ \\
\hline PAI & 175 & 1.37 & $-0,04$ \\
\hline$M 2$ & 2,13 & 163 & 0,00 \\
\hline PMz & 353 & $B, 00$ & $0,5 \%$ \\
\hline $\mathrm{M3}$ & $2: 47$ & 190 & 0.02 \\
\hline pha & 281 & 208 & 0.00 \\
\hline
\end{tabular}

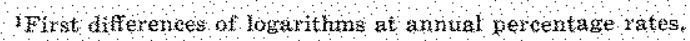


teriorates moving from M1 to M2 to M3. For the proposed measures, however, the growth of PM3 is more controllable than PM2. The results indicate that the adoption of these redefinitions would worsen monetary control, and that, except for PMI, intermediate targeting of quarterly growth rates would be subject to substantially larger control errors.

The dynamic simulations can also be used to compare the accuracy of control of the levels of the various aggregates on a quarterly basis. The results of these simulations are given in table 4 . The equations track the quarterly level of the aggregates quite well over the full period, with an average error of less than $\$ 1$ billion. The simulations of M1, PM1, and M2 track the level the best, with mean errors of $\$ 30$ million or less.

The RMSE and mean absolute error of the quarterly level simulations are $\$ 1$ billion or less for both MI and PMI, with MI control proving slightly superior again. The RMSE and mean absolute error of the dynamic forecasts for M2 and M3 levels are several times larger than those for M1 under either the existing or proposed definitions, but, as above, existing measures are generally superior to the proposed measures of M2 and M3.

While the results for one-quarter growth rates and quarterly levels from the simulations are compelling. policymakers also concern themselves with growth of aggregates over a longer period. Currently, intermediate targets for $\mathrm{M} 1$ and $\mathrm{M} 2$ are announced for fourquarter periods. Over such a span, the quarterly errors in growth rates tend to average to a smaller level. To investigate the extent of control over a four-quarter period, the dynamic simulations of the table 2 equations can be used to provide four-quarter growth rate estimates for the period from I/1961-II/1978. The results of comparing the predicted annual growth rates to the actual anmual growth rates for each aggregate are summarized in table 5 .

For annual periods, M1 and PM1 are substantially more controllable than the corresponding higher order M's. Control of existing aggregates deteriorates moving from M1 to M2 to M3; PM3, however, is more controllable than PM2 as indicated in table 3. The most startling result in table 5 is that control of M3, PM2, and PM3 fails to improve sufficiently when the control horizon moves from a one-quarter to a four-quarter period so that the RMSE is larger than the standard error of the respective equation in table 2 . The variances of errors in annual growth control for $\mathrm{M} 1, \mathrm{M} 2$, and $\mathrm{PM} 1$, however, are reduced by more than 30 percent of the RMSE for one-quarter forecasts.

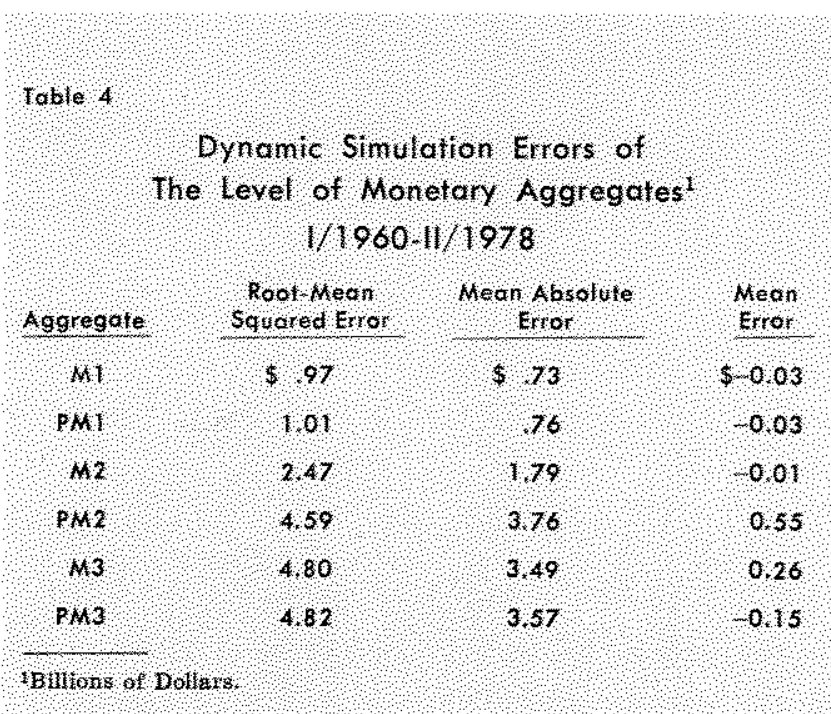

Tables

Control of Aggregale Growh Rates

For Fout $Q$ uatter Periods

$1 / 1961,1 / 1978$

\begin{tabular}{|c|c|c|c|}
\hline Aggregots & $\begin{array}{l}\text { Rool neart } \\
\text { Sougred Error }\end{array}$ & neon fsosolute & $\begin{array}{l}\text { Meno } \\
\text { Enor }\end{array}$ \\
\hline n1 & $112 \%$ & $0,91 \%$ & 0,06 \\
\hline PNI & 111 & 0,9 & 000 \\
\hline 12 & 146 & 146 & 0.02 \\
\hline$P M 2$ & 300 & 273 & 0.60 \\
\hline$M s$ & 199 & 153 & 0,02 \\
\hline $\mathrm{PAB}$ & 2,31 & 167 & $-0,20$ \\
\hline
\end{tabular}

Table 6

Controllability of a Broader Assef Measure

$11 / 1969,11 / 1978$

GROWTH RATES

\begin{tabular}{|c|c|c|c|}
\hline Aggregate & $\begin{array}{l}\text { Root Mean } \\
\text { Squated Etror }\end{array}$ & $\begin{array}{l}\text { Mean Absolute } \\
\text { Eron }\end{array}$ & $\begin{array}{l}\text { Mean } \\
\text { Eroo }\end{array}$ \\
\hline A & $183 \%$ & $133 \%$ & $.003 \%$ \\
\hline$P M I$ & 172 & 139 & -07 \\
\hline MI & 158 & 126 & 06 \\
\hline
\end{tabular}

LEVES

(Bilions of Dollars)

\begin{tabular}{|c|c|c|c|}
\hline A & $\$ 1.29$ & $\$, 98$ & $\$ 02$ \\
\hline$P A L$ & 1,20 & 95 & -03 \\
\hline$M I$ & 1,09 & 87 & 004 \\
\hline
\end{tabular}


Finally, since questions have been raised about the omission of other assets that are close substitutes for demand deposits from M1, it is useful to examine the controllability of such a broader aggregate. The Wenninger and Sivesind measure (referred to as A) consists of the sum of: current M1, corporate and state and local government savings deposits, NOW deposits, ATS savings deposits, credit union share drafts and demand deposits at thrifts, assets of money market mutual funds, repurchase agreements (RPs) at nonbank government securities dealers with nonfinancial corporations, and RPs at 46 large commercial banks. This measure was constructed for the period IV/1968-I/1979.

When the model above (equations 1-4) is estimated using this enlarged definition of "money" for the period II/1969-II/1978, the results are

$$
\begin{aligned}
& \beta_{0}=0, \beta_{1}=.662(5.08), \\
& \beta_{1}^{*}=858(16.69), \lambda=.771(5.16), \mathrm{h}^{2}=.32
\end{aligned}
$$

and a standard error of 1.84, where t-statistics are given in parentheses. For a comparison of controllability, the model was estimated and dynamically simulated over the same period for $\mathrm{M} 1$ and PM1. ${ }^{19}$ The resulting comparisons of simulations over the period II/1969-II/1978 are presented in table 6 for

\footnotetext{
11) When the Ml equation is estimated over the same period, the estimate of $\lambda$ rises to $0.797(t=-5.95)$. The point estimate of $\beta_{1}^{*}(0.785)$ is essentially the same and its t-statistic is 18.27 . The standard error of the equation is 1.54. A Chow test for structural change in the subperiods $1 / 1960-1 / 1969$ and II/1969-II/1978 rejects the structural change hypothesis. Similar results are obtained for PML, where $\lambda$ rises to 0.804 $(t=4.49)$ and $\beta_{5}^{*}$ is $0.784(t=17.35)$. The standard error for the PMl equation is 1.69 .
}

the quarterly growth rate equations as well as the aggregate level simulations.

The mean errors of the simulations of growth rates are quite small. The liquid asset measure, however, is substantially less controllable than M1 for both growth rates and levels. The comparisons generally indicate that PMI is also more controllable than $\mathrm{A}$, although not by as large a difference. The money measure, $A$, is an inferior measure by which to conduct monetary policy. ${ }^{20}$

\section{SUMMARY AND CONCLUSION}

The Board of Governors is currently considering revising the definitions of the monetary aggregates. One important criterion that should influence the process of redefining these aggregates is the controllability of these measures through Federal Reserve actions. This criterion is especially crucial if the aggregates are to be used as intermediate targets of monetary policy.

Given the framework developed in this article for assessing Federal Reserve control of the monetary aggregates, the evidence indicates that the measures proposed by the Board's staff in January 1979 are subject to greater control errors than current aggregate measures, except for proposed M1.

\footnotetext{
" Since the Weminger and Sivesind study, the Board of Governors has released more comprehensive measatres of repurchase agreements at commercial banks. See Noman N. Bowsher, "Repurclase Agreenents," this Review (September 1979), pp. 17-22, for a description of this clata. When the Wemmer and Sivesind A neasure is adjusted by taking out RPs at 46 large commercial banks and adding in RPs at all commercial banks, the controllability of the resulting aggregate deteriorates further. A detailed comparison is not reported here because data for the comparison is only available for the period since the fourth quarter of 1974 .
}

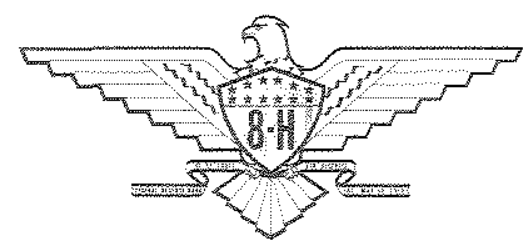

